\title{
PROFESSORES DE HISTÓRIA INICIANTES: ENTRE SABERES E PRÁTICAS ${ }^{1}$
}

\author{
TEACHERS BEGINNERS HISTORY: BETWEEN KNOWLEDGE AND PRACTICES
}

\author{
Osvaldo Mariotto Cerezer ${ }^{2}$
}

Selva Guimarães ${ }^{3}$

\begin{abstract}
RESUMO: O estudo apresenta alguns aspectos importantes relacionados à fase inicial da carreira profissional e suas implicações com a formação da identidade profissional docente, tomando como referência a análise de narrativas orais de professores de História iniciantes. O principal instrumento utilizado para o registro das vozes dos colaboradores foi a entrevista oral, inspirada nos procedimentos metodológicos delineados pela história oral temática. A opção pela história oral temática, nas investigações no campo da educação, se justifica por entendermos que proporciona uma mediação significativa entre dois campos do conhecimento, história e educação. A análise dos dados foi orientada pela análise qualitativa. Os aspectos salientados pelas vozes dos professores iniciantes demonstram que ainda é necessário um investimento maior no que se refere a formação de professores de História para o exercício da docência na Educação Básica.
\end{abstract}

Palavras-chave: Formação de professores. Professor Iniciante. Ensino de História.

ABSTRACT: The study presents some important aspects related to the early stage of working life and its implications with the formation of the teaching professional identity, with reference to the analysis of oral narratives of history teachers beginners. The main instrument used to record the voices of employees was the oral interview, inspired by the methodological procedures outlined by the thematic oral history. The choice of thematic oral history, with investigations in the field of education, is justified because we believe it provides a meaningful mediation between two fields of knowledge, history and education. The data analysis was guided by qualitative analysis. The aspects highlighted by the voices of beginning teachers surveyed show that increased investment as regards the training of history teachers to carry out teaching in basic education is still needed.

Keywords: Teacher Formation. Teacher Beginner. History Teaching.

1 O presente texto faz parte dos estudos desenvolvidos na tese de doutorado denominada Diretrizes curriculares para o ensino de história e cultura afro-brasileira e indígena: implementação e impactos na formação, saberes e práticas de professores de história iniciantes (Mato Grosso, Brasil), realizada no Programa de Pós-Graduação em Educação da Universidade Federal de Uberlândia (UFU), em fevereiro de 2015 . O estudo contou com apoio de Bolsa FAPEMAT/CAPES.

2 Professor adjunto do Departamento de História da Universidade do Estado de Mato Grosso (UNEMAT) - Campus de Cáceres. Doutor em Educação pela Universidade Federal de Uberlândia (UFU).

3 Professora Titular da Faculdade de Educação da Universidade Federal de Uberlândia (UFU). Doutora em História pela Universidade de São Paulo. 


\section{Introdução}

Nosso estudo pretende apresentar e discutir algumas questões que consideramos importantes no que se refere ao início da carreira docente do professor de História, procurando compreender as especificidades e complexidades que atravessam o desenvolvimento do exercício da docência nos primeiros anos de atuação profissional, com ênfase para as dificuldades, desafios e os caminhos percorridos para o enfrentamento das problemáticas inerentes ao fazer-se professor de História na Educação Básica e sua relação com formação da identidade docente.

Os sujeitos participantes do estudo foram onze professores egressos de três Cursos de Licenciatura em História do Estado de Mato Grosso ${ }^{4}$ em fase inicial da carreira docente. Para fundamentar nosso estudo, utilizamos como referência o conceito de "professor iniciante" a partir das definições da Huberman (1992) e Garcia (1999), que adotam a categoria de professor iniciante para aqueles que possuem até 05 anos de prática docente. Nesse sentido, esse conceito foi utilizado por nós como critério para analisarmos as temáticas propostas por este estudo. Os colaboradores ${ }^{5}$ do estudo possuíam de 4 (quatro) meses a 4 (quatro) anos de tempo médio de atuação docente na Educação Básica em escolas públicas e privadas de diferentes regiões de Mato Grosso.

Inspirados em Huberman (1992) e Garcia (1999), compreendemos por professor iniciante, o docente em fase inicial da carreira profissional, com até 05 anos de atuação profissional. De acordo com os autores, a fase inicial da carreira é uma etapa marcada por complexas situações relacionadas ao "aprender a ser professor" na prática em ambientes instáveis e incertos, exigindo dos novos educadores o desenvolvimento de atitudes de experimentação, baseadas em erros e acertos, bem como na persistência e enfrentamento de situações problemas.

\footnotetext{
4 Foram entrevistados professores iniciantes egressos dos Cursos de Licenciatura em História da Universidade do Estado de Mato Grosso (UNEMAT), Campus de Cáceres, e Universidade Federal de Mato Grosso (UFMT) Campus de Cuiabá e Rondonópolis.

${ }^{5}$ As entrevistas foram realizadas entre os anos de 2012 a 2014.
} 
Segundo García (1999, p. 26), trata-se de uma "[...] etapa correspondente aos primeiros anos de exercício profissional do professor, durante os quais os docentes aprendem na prática, em geral, através de estratégias de sobrevivência".

Huberman (1992) destaca cinco fases distintas no desenvolvimento da carreira profissional docente: exploração, estabilização, diversificação ou questionamento, conservadorismo e desinvestimento. Considera os 2-3 primeiros anos como sendo a fase de "exploração" onde o professor passa por diferentes experiências desafiadoras, avaliando o desenvolvimento em termos de competência profissional. Segundo constata o autor, a fase exploratória pode ser

[...] sistemática ou aleatória, fácil ou problemática, concludente ou enganadora. No caso concreto do ensino, a exploração é limitada por parâmetros impostos pela instituição: as pessoas têm oportunidade de "explorar" poucas turmas para além das suas, poucos estabelecimentos, para além do seu, poucos papéis para além do de responsável pelas suas turmas. (HUBERMAN, 1992, p. 39).

O autor salienta que o início da carreira é um momento de socialização e de muitos desafios a serem enfrentados pelos professores. Nesse período, considera, com base em autores como Fuller (1969), Field (1979) e Watts (1980), dois importantes estágios de desenvolvimento: a "sobrevivência" e a "descoberta". Na fase da "sobrevivência" destaca-se o denominado "choque do real" e os aspectos relacionados com "[...] o tactear constante, a preocupação consigo próprio ("Estou-me a aguentar?"), a distância entre os ideais e as realidades quotidianas da sala de aula, a fragmentação do trabalho" (HUBERMAN, 1992, p. 39). O segundo estágio denominado "descoberta" é marcado pelo entusiasmo, pela experimentação e pela exaltação, por estar em seu ambiente de trabalho, local repleto de novidades.

A atuação profissional dos colaboradores está assim distribuída: 5 (cinco) professores iniciantes atuavam em escolas públicas (estadual e municipal) e em escolas privadas, 5 (cinco) professores atuavam, exclusivamente, em escolas públicas e apenas 1 (um) professor atuava somente em escolas privadas. 
O principal instrumento utilizado para o registro das vozes dos colaboradores foi a entrevista oral, inspirada nos procedimentos metodológicos delineados pela história oral temática. A opção pela história oral temática, nas investigações no campo da educação, se justifica por entendermos que proporciona uma mediação significativa entre dois campos do conhecimento, história e educação. Este diálogo possibilita ampliar a compreensão a respeito da complexa rede de experiências vividas pelos professores iniciantes e sua inserção no campo profissional.

Para Portelli (1997, p. 15),

a História Oral é uma ciência e arte do indivíduo. Embora diga respeito - assim como a sociologia e a antropologia - a padrões culturais, estruturas sociais e processos históricos, visa aprofundálos, em essência, por meio de conversas com pessoas sobre a experiência e a memória individuais e ainda por meio do impacto que estas tiveram na vida de cada uma.

A analise dos dados foi orientada pela análise qualitativa. Nesse contexto, compartilhamos com Bogdan e Biklen (1994) que compreendem a abordagem qualitativa como aquela que, "[...] exige que o mundo seja examinado com a ideia de que nada é trivial, que tudo tem potencial para se constituir numa pista que nos permita estabelecer uma compreensão mais esclarecedora do nosso objecto de estudo" (1994, p. 49). Nessa direção, compreendemos que os relatos de experiências sobre a formação acadêmica e a atuação profissional dos colaboradores foram importantes para compreendermos a relação entre os estudos desenvolvidos nos cursos de História sobre formação de professores e os impactos na prática docente dos egressos nas escolas.

Uma característica importante da investigação qualitativa é a importância atribuída às representações/significados construídos pelos colaboradores sobre o tema em estudo. Assim, as percepções dos colaboradores sobre suas experiências são aspectos relevantes para os quais o pesquisador precisa lançar um olhar atento e minucioso para não perder os detalhes que podem revelar informações importantes.

Nesse sentido, 
[...] a investigação qualitativa é descritiva. [...]. Na busca de conhecimento, os investigadores qualitativos não reduzem as muitas páginas contendo narrativas e outros dados a símbolos numéricos. Tentam analisar os dados em toda a sua riqueza, respeitando, tanto quanto o possível, a forma em que estes foram registrados ou transcritos (BOGDAN, BIKLEN, 1991, p. 48).

A compreensão ampla e minuciosa proporcionada pela abordagem qualitativa sobre o objeto em estudo, onde os significados são tão ou mais importantes que os dados, são consideradas uma das suas características centrais. Dessa maneira, "os investigadores qualitativos interessam-se mais pelo processo do que simplesmente pelos resultados ou produtos" (BOGDAN, BIKLEN, 1991, p. 49).

Em educação, as narrativas registradas por meio das fontes orais, constituem-se em importante processo para a compreensão da realidade educacional e formação de pesquisadores e professores. De acordo com Delgado (2006, p. 15),

[...] a História Oral é um procedimento metodológico que busca, pela construção de fontes e documentos, registrar, através de narrativas induzidas e estimuladas, testemunhos, versões e interpretações sobre a História em suas múltiplas dimensões. Para o campo de investigações sobre o ensino da História, a história oral se apresenta como uma estratégia importante para alcançar as experiências, memórias e significados dos professores, possibilitando com isso, a oportunidade de compreensão, análise e intervenção no espaço educacional.

Nesse contexto, buscamos compreender "o mundo do sujeito, os significados que atribui às suas experiências cotidianas, sua linguagem, suas produções culturais e suas formas de interações sociais" (MINAYO, 2007, p. 21).

Em nosso estudo optamos por não identificar os colaboradores pelos seus nomes originais. Os identificaremos por Professor(a) Iniciante I, Professor(a) Iniciante II, e, assim, sucessivamente.

Ao nos propormos a analisar os impactos da formação inicial na prática docente de professores de História iniciantes egressos dos cursos de Licenciatura em História de Mato Grosso, procuramos estabelecer uma relação direta entre os 
significados, saberes e práticas produzidas na formação inicial, e as experiências construídas no início da atuação docente na Educação Básica.

Acreditamos que as relações estabelecidas por este estudo podem contribuir para uma compreensão mais ampla e detalhada das especificidades e complexidades que compõem o cenário de constituição da identidade profissional docente. Portanto, acreditamos que essa relação é relevante para os objetivos deste estudo, principalmente para a reflexão da estrutura curricular dos cursos de formação de professores de História, as permanências, os avanços e as limitações.

Partindo desses argumentos, estabelecemos um diálogo com os professores de História iniciantes em relação às suas experiências na fase inicial da carreira, momento repleto de expectativas, conflitos e novas aprendizagens em um território (sala de aula) conhecido, pelas experiências como aluno durante os anos de escolarização. Porém, ao entrar na sala de aula como professor iniciante, o espaço/território, aparentemente "conhecido" transforma-se em "desconhecido", às vezes assustador e desestabilizador.

$\mathrm{Na}$ condição de professor iniciante, a sala de aula apresenta-se como um território ainda inexplorado, processo este que exige um alto nível de esforço, empenho pessoal na busca de compreensão da dinâmica de funcionamento da sala de aula.

A nosso ver, o domínio da sala de aula representa um dos principais desafios do professor iniciante. Ele sabe qual é o papel que um professor desempenha, mas ainda não sabe como desempenhar esse papel. Conhecer a sua condição de professor implica reconhecer a dinâmica mutante e imprevísivel que a escola, a sala de aula e seus distintos personagens representam a cada dia.

Os relatos das experiências docentes em fase inicial da vida profissional constituem-se em reveladores da complexidade da profissão docente, em particular do professor de História, podendo contribuir para que outros professores possam refletir e buscar formas e/ou alternativas de formação, de re/construção de saberes na atuação em sala de aula. 


\section{Narrativas de professores iniciantes e os desafios do ingresso na carreira docente}

Nesse espaço, privilegiaremos os relatos dos professores iniciantes sobre as experiências vivenciadas na fase inicial da carreira docente. Nesse sentido, ao solicitarmos à Professora Iniciante I que relatasse as experiências do ingresso na escola, ela assim se manifestou:

Não foi tão assustador porque eu já tinha uma experiência com aulas na igreja (Fui e sou professora da Escola Bíblica). Isso para mim foi de grande ajuda porque já sabia interagir com adolescentes e crianças. Mas a realidade não é a mesma, é só uma vez por semana e o tempo é reduzido. Na escola convencional me deparei com uma realidade totalmente diferente $e$ isso em assustou um pouco. Tive muita dificuldade em lidar com 0 comportamento das turmas (inclusive na escola particular), mas com o tempo fui adquirindo experiência e estratégias para poder me sair bem. Confesso que até hoje, no início das aulas, dá um friozinho na barriga, afinal, tudo é novo (Professora Iniciante I).

"Afinal, tudo é novo!" A frase da professora nos remete às discussões mencionadas no texto sobre os impactos, perspectivas e desafios enfrentados pelo professor ao iniciar sua atuação em sala de aula. Espaço de incertezas, desafios e transformações constantes. Esse aspecto faz parte da experiência de outros professores iniciantes colaboradores deste estudo.

Para a Professora Iniciante $V$, os principais obstáculos por ela enfrentados ao ingressar na sala de aula como professora, estão relacionados à "prática docente, a falta de experiência, pois a universidade deixa a desejar em relação às aulas/atividades de prática". Em seu argumento, salientou que a formação universitária no curso de História foi essencialmente teórica, deixando a "prática em segundo plano". A colaboradora narrou sobre as inúmeras dificuldades ao iniciar a carreira docente, dificuldades que ultrapassavam a questão pessoal, como o comportamento dos alunos, a deficiência física da escola, a falta de material didático para o desenvolvimento das atividades das aulas. Nesse sentido, a colaboradora afirmou: 
Havia uma série de pontos que eu não estava preparada, eu tive que estudar bastante para começar as aulas. No início eu trabalhei em escola de periferia, tinha a questão familiar dos alunos e isso foi bastante complicado, a deficiência física da escola, não havia carteiras para todos os alunos, havia poucos recursos didáticos na escola, eu tinha o meu próprio "kit de recursos" que eu levava para a escola, eu tive que improvisar (Professora Iniciante V).

Ao fazer referência aos problemas e dificuldades enfrentadas no início da carreira docente, a Professora Iniciante II afirmou:

O que mais pesou foi a questão do preconceito dos outros colegas em relação a quem está iniciando. Dizer que você não tem domínio de sala, isso pesava em mim. Eles não me questionavam sobre o meu conteúdo, de como eu estava trabalhando mediante a sala, mas sim por eu não ter domínio de sala de aula, então isso pesava muito.

Por sua vez, a Professora Iniciante I relatou as impressões, desafios e angústias que envolveram a sua iniciação como professora de História em escola pública.

\begin{abstract}
Eu considero um início incerto para qualquer um. Tenho certeza que entramos com muito gás, talvez além do que devia. Quando a ficha vai caindo provoca uma angústia muito grande porque nos deparamos com uma realidade um pouco diferente daquilo que pensávamos. Essa angústia é provocada pela rotina em sala de aula, pela resposta dos alunos em relação ao interesse pela aula e também pelo contracheque. Certamente o iniciante não consegue visualizar a complexidade da carreira. Com o passar do tempo ele começa a entender onde está se metendo.
\end{abstract}

A Professora Iniciante VI afirmou que a inserção na Educação Básica se deu ainda durante a realização do Curso de História, atuando como professora interina em uma escola pública estadual. Ao concluir o curso, passou a atuar como interina 6 em uma escola pública municipal, num Assentamento da Reforma Agrária no município de Cáceres. De acordo com a colaboradora, "foi uma das experiências mais fantásticas da minha vida".

\footnotetext{
${ }^{6}$ Professor substituto, não concursado.
} 
primeiro, eu fui trabalhar numa sala multiseriada e eu nem sabia o que era multi-seriado, trabalhei com crianças de cinco a nove anos e, no período da noite, eu dava aulas de geografia, religião e história para a EJA. Fiquei dez meses nesse assentamento e deu para desenvolver um trabalho muito bacana com aquelas crianças.

A colaboradora afirmou ainda que as experiências adquiridas nas duas escolas, durante e depois da formação acadêmica, foram importantes para o trabalho em outra escola como professora efetiva. No entanto, ao ingressar na escola, tornaram-se claro algumas dificuldades, particularmente em relação a alguns temas que, em sua opinião, foram "pouco discutidos".

Faltou muito ter um aprofundamento maior de alguns temas, muitas vezes foram só pinceladas, e também acho que a universidade falha muito em relação às aulas práticas, de mostrar ao aluno a realidade da nossa sociedade, porque existe esse jargão "universidade sem muros", mas na verdade é uma das piores coisas porque a universidade é cheia de "muros", é uma fortaleza essa universidade na verdade (Professora Iniciante VI).

Nas críticas ao Curso de História frequentado, destacou a existência de professores formadores não comprometidos com formação de novos professores. Por outro lado, argumentou que "teve ótimos professores, com matérias muito boas, foi na universidade que eu descobri meu amor pela questão indígena e pela questão da América Latina".

As dificuldades inerentes à profissão docente, particularmente na sua fase inicial, no trato das complexas questões que envolvem a sala de aula e seus personagens, foram analisadas pela Professora Iniciante $I$ :

Minha maior dificuldade foi lidar com a indisciplina, ainda não consigo entender como os alunos vão para a escola, que é um lugar de adquirir conhecimento, para, simplesmente, não fazer nada e ainda prejudicar o bom andamento da aula atrapalhando os colegas que querem estudar. Tento resolver conversando, negociando. Meu último recurso é procurar ajuda da coordenação pedagógica, quando busco esse recurso é porque a situação está insustentável.

Ao ser questionada sobre como lidou na fase inicial da carreira com a temática africana, afro-brasileira e indígena, a Professora Iniciante $I$ afirmou que 
buscou inspiração/referências em outros professores para desempenhar suas funções.

\begin{abstract}
Acho que não tem receita para isso, até tentei pensar em alguma referência, mas quando entrava na sala as coisas não saíam como o imaginado. Quando fiz o curso de Magistério isso era um questionamento frequente por parte dos alunos do curso e nossa professora de estágio dizia que não havia receita, iríamos aprender sofrendo, na rotina. Isso foi bom porque aprendi com meus próprios métodos (se tenho algum...(risos), a confiar mais em mim. Aprendi também que em cada sala a nossa atuação é diferente. Isso nos faz amadurecermos e termos algumas estratégias em mente, mas nada surpreendedor (Professora Iniciante I).
\end{abstract}

Na mesma direção, a Professora Iniciante II afirmou que a busca de referências em ex-professores foi importante para a construção da sua identidade docente, das formas de pensar e organizar o trabalho a ser desenvolvido e das formas de agir em sala de aula.

Eu não queria ser professora, mas quando eu acabei indo pra educação eu tinha alguns pontos de referência. Tinha uma professora de Português, ela me incentivava e eu acho que eu uso muito isso hoje que é tentar corrigir para os alunos escreverem corretamente; um professor de Matemática, porque eu achava interessante quando ele chegava à sala de aula e sempre colocava um pensamento antes de iniciar as aulas. E no Ensino Médio eu tive uma professora de Geografia, a forma de ela trabalhar o conteúdo, isso fez com que eu me espelhasse. Na graduação, eu "explorava" muito o professor de Didática, eu me espelhava e questionava sobre os materiais que eu poderia usar para trabalhar (Professora Iniciante II).

A Professora Iniciante VI, destacou que, "possuía algumas experiências" de vida e de formação e que estas a auxiliavam no trato da complexidade que a sala de aula representa, sobretudo na relação entre o educador e o educando.

Para a colaboradora VI, "as experiências são construídas todos os dias porque tenho que aprender a lidar com muitos acontecimentos naquele momento. Tenho o cuidado, quando dou aulas, de lembrar que cada aluno é um mundo diferente, cada um tem uma vivencia, uma história, um valor, um problema, uma dificuldade, uma tristeza". Afirmou que sua intenção como educadora era "fazer com que os alunos vejam além da sala de aula e, 
principalmente, que sejam melhores como pessoas, porque eu vejo que na minha matéria eu tenho essa possibilidade".

Nesse contexto, a Professora Iniciante VII lembrou como o início da carreira "foi um período traumático". Segundo ela:

A sensação de insegurança, de medo é muito grande porque a gente ouve muita história de colegas que já se formaram na área, da violência, do não domínio de sala, da coordenação que fica te cobrando dizendo que você tem que fazer os alunos ficar sentados, que eles têm que ficar quietos, e o professor de história é meio avesso a essas coisas, ele quer fazer uma aula mais dinâmica, instigar os alunos a pensar um pouco mais e isso as vezes incomoda certas coordenações (Professora Iniciante VII).

Para essa colaboradora isto se deve pelo fato de que durante o curso de graduação, ela não fez Estágio na escola, pois o curso era de Licenciatura e Bacharelado, logo a inserção na escola era limitada. "Eu não fiz Estágio, não estive no "chão da escola" quando eu fazia faculdade, a minha experiência foi quando eu resolvi trabalhar na área." Para a professora, as dificuldades iniciais a levaram a pensar em desistir da profissão. "No começo eu fiquei frustrada, teve uma hora que pensei em largar esse ofício porque eu não tinha aptidão para exercê-lo, eu pensei várias vezes, a gente fica um pouco deprimida achando que o problema é nosso, mas não é".

Segundo o Professor Iniciante IV, os problemas por ele enfrentados no início da carreira estão relacionados ao modelo de Curso de História por ele frequentado (Licenciatura e Bacharelado em História). Lembrou que o Curso não "dava muitos elementos para a prática docente". As discussões e estudos, segundo ele, voltados para a formação e atuação docente, foram restritos aos seminários apresentados pelos pares e para os pares. Salientou, ainda que o contato com a sala de aula na Educação Básica ficou restrito à realização de um curto período de estágio no final do curso $^{7}$, o que repercutiu negativamente em sua formação, criando muitas dificuldades para o entendimento e para a atuação no espaço escolar.

7 O colaborador salienta que o Estágio realizado no final do curso ocorreu por causa do ingresso, via concurso, de uma Professora de Didática do Ensino de História. 
Para a Professora Iniciante VIII o início da carreira foi "muito pesado porque a gente não tinha experiência e o Estágio realizado na graduação não deu uma boa base para ingressar numa sala de aula". Esses fatos fazem parte dos relatos da maioria dos nossos colaboradores.

A Professora Iniciante $I X$, ao se lembrar do início da carreira, afirmou que "foi difícil, eu observei muito outras professoras, comecei a observar elas, fui recorrendo aos textos sobre prática de ensino, as experiências que davam certo ou não". Um aspecto importante no relato dos professores refere-se à busca de referências em professores mais experientes para auxiliá-los no desenvolvimento das atividades.

Sobre esse aspecto, a Professora Iniciante VIII afirmou que

No início a gente caminha um pouco só, um pouco não, totalmente sozinhos! Tem a coordenação da escola, só que eles não dão um respaldo pra você, eu acho que não há um cuidado com o professor que está iniciando, pelo menos eu senti isso comigo, não se tem um cuidado, um preparo.

Nesse sentido, considerou valioso o acompanhamento e a supervisão na fase inicial da carreira. No entanto, ressalva que a supervisão

poderia ser mais vantajosa dentro da universidade no Estágio Supervisionado, porque quando eu fiz o curso, eu tive poucas aulas, acredito que apenas duas aulas na escola. Deveria ter mais aulas práticas de estágio. Eu tive estágio no último ano, eu achei pouco.

A Professora Iniciante VIII afirmou que, ao ingressar na escola, não encontrou maiores dificuldades para ministrar as aulas de História, lembrou que foi orientada a seguir o "livro didático, mas com toda a liberdade para trabalhar em sala de aula". Afirmou ter ocorrido resistência por uma parcela dos alunos em relação ao estudo da História. Argumentou que tentava, ao iniciar as aulas, defender a importância da história para que os alunos compreendessem o seu significado. Nesse contexto, reafirmou que a realidade da sala de aula é muito diferente da escola imaginada no ambiente universitário.

A universidade é muito diferente da sala de aula. Eu me lembro da professora que era nossa coordenadora de Estágio, ela falava com 
muita paixão, só que dentro da sala de aula é um pouco diferente, talvez não seja tão apaixonante, mas ao longo do tempo vamos construindo, adquirindo confiança dos alunos, não fica tão pesado (Professora Iniciante VIII).

A questão da indisciplina escolar foi um aspecto ressaltado pela Professora Iniciante $I X$, dando ênfase para o uso excessivo de tecnologias pelos alunos, principalmente do celular. A professora relembrou que tentava atrair a atenção dos alunos, utilizando-se de técnicas que aprendeu no teatro, atividade que também desenvolvia, defendendo a ideia da necessidade do professor ser um "contador de histórias".

Para a Professora Iniciante IX, o ingresso na carreira docente foi considerada uma

experiência, a princípio, bastante desafiadora, porque você vai errando para aprender. Tem vários colegas de trabalho que às vezes querem te ajudar, te orientam e como estamos entrando nesse ambiente, acabamos pegando uma coisa de um, outra coisa de outro, até chegar a nossa própria forma de fazer as coisas, então, a gente precisa um pouco dos colegas para começar a fazer as coisas.

Apesar de considerar importante o auxílio de colegas experientes, a professora sublinhou que "às vezes penso muito bem na ajuda que um colega está me dando porque, às vezes, eu não concordo com algumas coisas e tento fazer do meu jeito". Ao abordar a presença do racismo e da discriminação racial na sociedade brasileira, foi direta: "há muito preconceito ainda". Ela declarou ter sido vítima de preconceito pelo fato de ser negra:

Hoje, pelo fato das pessoas saberem que existe uma punição, talvez o preconceito seja velado, mas ainda tem sim! A gente sempre discutia na universidade, debaixo da pele todo mundo é igual, não tem diferença, mas infelizmente a sociedade brasileira não pensa dessa forma. Eu já sofri preconceito ao chegar em um lugar e as pessoas me "olharem com um olhar desconfiado", com "olhar torto", ficar "vigiando" para ver se você não vai fazer alguma coisa de errado, falo isso por experiência própria (Professora Iniciante IX). 
As vozes dos professores iniciantes egressos do Curso de Licenciatura em História de Mato Grosso expressam algumas características que demonstram fragilidades dos cursos no que tange à formação para a docência, aspecto, tradicionalmente ignorado ou, superficialmente tratado pelos Cursos de História, reduto de profissionais mais voltados para a formação em pesquisa historiográfica, em detrimento da formação de professores para o ensino de História nas escolas da Educação Básica. Diante disso, apesar de reconhecermos os avanços significativos em termos de políticas educacionais, currículos, pesquisas e produções sobre formação e carreira docente, a realidade atual demonstra que há muito a ser conquistado ainda.

\section{Considerações sobre os desafios da prática pedagógica no início da carreira docente}

As dificuldades, desafios e incertezas comuns no início da carreira docente foram recorrentes nas narrativas dos nossos colaboradores. Esses aspectos são comuns, mas também singulares, pois nada é fixo ou cristalizado, a sala de aula é um espaço de novidades, boas ou não; é um espaço em movimento, em (re)construção constante, alunos e professores se (re)constroem, se (re)inventam no processo de ensino e aprendizagem em História. "La transición de alumno a profesor novel se caracteriza por un conjunto de tensiones y de dilemas. Sentirse profesor(a) encierra un proceso en el que confluyen convicciones y valores, a veces contradictorios: los de alumno y los de profesor" (FLORES, 2009, p. 88).

Fenelon (1983), em texto da década de 1980, chamava a atenção para os inúmeros problemas e dificuldades enfrentadas pelos professores iniciantes ao ingressar na carreira docente e os desafios de lidar com tal complexidade. Três décadas depois, há inúmeras semelhanças nas condições de formação inicial nos cursos superiores e na realidade escolar na educação básica.

Fenelon (2008) salienta que ao ingressar na carreira, o professor iniciante vai ter que

História \& Ensino, Londrina, v. 21, n. 2, p. 125-150, jul./dez. 2015 
[...] enfrentar a realidade de uma sala de aula com 40/50 alunos, $30 / 40$ horas semanais e péssimas condições de infraestrutura, para não falar do desinvestimento, a remuneração aviltante, na maioria das vezes se sente perdido, não sabe o que vai fazer. Passou quatro anos estudando a sua disciplina e de repente se vê perplexo diante da realidade - quase sempre não tem segurança da sua própria concepção de História, de ensino - e na confusão tenta reproduzir o que aprendeu com a intenção de fazê-lo o melhor possível. Sente-se perdido até mesmo quanto aos critérios de escolha do livro didático a ser adotado, dentre a profusão de novos lançamentos com visuais modernos e conteúdos antiquados (FENELON, 2008, p. 27).

Neste cenário, acreditamos que o Estágio Supervisionado, por meio dos estudos teóricos e sua vinculação com a realidade escolar, bem como as atividades práticas desenvolvidas na academia e na escola, apresentam-se como um momento importante e singular na formação dos futuros professores por proporcionar um contato mais concreto e realista com o futuro espaço de atuação profissional, auxiliando na compreensão da complexidade e das singularidades, traçando possibilidades de ação que o professor pode exercer no cotidiano escolar. Porém, para além do Estágio, os cursos de formação inicial em História precisam romper com a dicotomia licenciatura-bacharelado (cf. FENELON, 1984) que permanece latente nas diversas instâncias formativas dos cursos, assim como a necessidade de assumir a formação para a pesquisa e produção do conhecimento histórico, aliadas à formação para a prática da docência escolar, campo de atuação da imensa maioria dos professores egressos dos Cursos de História.

Nesse contexto, acreditamos que os cursos de formação inicial, ao assumir a formação para a docência enquanto objetivo final, precisam responder às demandas de uma sociedade globalizada e multicultural, realidade que não comporta mais discursos e práticas que não incluem essa realidade em suas ações políticas e pedagógicas.

Nesse sentido, Azzi (2005, p. 47) observa que

[...] a prática docente, expressão do saber pedagógico, constituise numa fonte de desenvolvimento da teoria pedagógica. As necessidades práticas que emergem do cotidiano da sala de aula demandam uma teoria. O processo de ensino, em sua estrutura e 
funcionamento, caracteriza-se como práxis, na qual teoria e prática se determinam, gerando juntamente com o objeto-sujeitos desse processo - o aluno - um saber próprio da atividade docente que, ao incorporar-se àquele que exerce sua ação sobre um determinado objeto visando à sua transformação, transforma também esse sujeito - no caso - o professor, que se enriquece durante o processo. O trabalho docente é um processo de objetivação do professor. Objetivação em si, quando representa apenas adaptações ou interiorizações do mundo ou, objetivação para si, quando é criativa, quando é sintetizadora.

Acreditamos que a construção da identidade docente passa por várias reinvenções ao longo do percurso profissional. Na fase inicial, onde os desafios e os problemas se apresentam de forma mais intensa, o auxílio de professores mais experientes se mostra uma possibilidade concreta para o enfrentamento dos problemas de forma mais segura e eficaz (cf. GUIMARÃES, 1997). Nesse processo, para Garcia (1999), o ingresso na carreira docente, especialmente o primeiro ano de atuação, representa um dos momentos mais desafiadores para o professor iniciante. De acordo com o autor, nesse período, o professor iniciante passa por um "intenso processo de aprendizagem - do tipo ensaio/erro na maioria dos casos - caracterizado por um princípio de sobrevivência e por um predomínio do valor prático" (GARCIA, 1999, p. 114).

O reinventar-se a cada dia como professor, a busca pelas metodologias e didáticas mais apropriadas para os diferentes contextos encontrados nas distintas turmas/salas de aula, são aspectos fundamentais do "ser professor" e da construção da identidade docente e sua relação direta com os desafios constantes e imprevisíveis que a profissão apresenta. Buscar referências em outros professores pode ser promissor, mas nem sempre funciona, pois são situações diferentes, específicas e a "receita", como salientado pela professora iniciante, pode não funcionar, pois os "ingredientes" (professor, alunos, escola, contexto histórico e social) são diferentes.

Pimenta (2005, p. 17-18) ao analisar a formação inicial e sua relação intrínseca com a formação da identidade docente, argumenta que

Para além da finalidade de conferir uma habilitação legal ao exercício profissional da docência, do curso de formação inicial se espera que forme o professor. Ou que colabore para sua formação. 
Melhor seria dizer que colabore para o exercício de sua atividade docente, uma vez que professorar não é uma atividade burocrática para a qual se adquire conhecimentos e habilidades técnicomecânicas. Dada à natureza do trabalho docente, que é ensinar como contribuição ao processo de humanização dos alunos historicamente situados, espera-se da licenciatura que desenvolva nos alunos conhecimentos e habilidades, atitudes e valores que Ihes possibilitem permanentemente irem construindo seus saberes-fazeres docentes a partir das necessidades e desafios que o ensino como prática social Ihes coloca no cotidiano. Espera-se pois que mobilize os conhecimentos da teoria da educação e da didática necessários à compreensão do ensino como realidade social, e que desenvolva neles a capacidade de investigar a própria atividade para, a partir dela, constituírem e transformarem os seus saberes-fazeres docentes, num processo contínuo de construção de suas identidades como professores.

O experimentar, ousar, criar estratégias visando atender as necessidades que se apresentam a cada dia faz parte do processo contínuo da docência. Nesse processo, "la tensión entre creencias e ideas sobre la enseñanza y sobre lo que significa ser profesor y su práctica constituye un aspecto central en la formación de la identidad profesional" (FLORES, 2009, p. 88-89).

Sobre a formação da identidade profissional, Moita (1992, p.116) salienta que, "o processo de construção de uma identidade profissional própria não é estranho à função social da profissão, ao estatuto da profissão e do profissional, à cultura do grupo de pertença profissional e ao contexto sociopolítico em que se desenrola".

Pagès (2004), Guimarães e Zamboni (2008) defendem que a formação do professor de História precisa levar em consideração os múltiplos aspectos, os variados espaços formativos que, muitas vezes, são negligenciados pelos cursos de formação. Isto pode enriquecer a formação do professor para o desenvolvimento das atividades diante da complexidade e dos desafios representados pela profissão.

Para Pagès (2004, p. 157),

¿No sería conveniente plantearse la necesidad de completar la formación de los futuros profesores con una formación profesional que no sea un añadido a su formación científica? Para ser profesor o profesora no basta con saber lo que debe enseñarse, es necesario saber muchas otras cosas. Sin duda, nadie puede 
enseñar lo que no sabe. En consecuencia, para enseñar es necesario saber pero no basta sólo saber para saber enseñar. Enseñar es comunicar. $Y$ en cualquier acto comunicativo hay que tener en cuenta: a) la formación para la comunicación, la adecuación de lo que se comunica, del discurso, al medio y al contexto, el aprendizaje de determinadas herramientas, etc. Hay que formar al comunicador para que conozca las características y los medios de la comunicación educativa; b) las personas a las que se les comunica algo, con las que se establece algún tipo de comunicación, en nuestro caso los alumnos y las alumnas de secundaria, su predisposición ante lo que les queremos comunicar, sus propósitos y sus intereses para aprender aquello que les comunicamos; y c) lo que se comunica, este caso el conocimiento histórico, y cómo debemos comunicarlo para obtener aprendizajes. $Y$, además, el contexto en el que se realiza la comunicación, contexto que incluye desde las finalidades o propósitos educativos que la administración educativa otorga a los saberes escolares, el contexto social y cultural, hasta la institución en la que se realiza y la organización espacio-temporal en la que tiene lugar (organización del espacio aula y tiempo de duración de la comunicación). La didáctica de la historia pretende dar respuesta a esta formación. Se ocupa de enseñar el oficio de enseñar historia, de formar como profesores a los estudiantes de historia. Pero, ¿en qué consiste preparar para ser profesor o profesora de historia?, ¿qué significa formar las competencias en didáctica de la historia de los futuros profesores? En mi opinión, preparar a un profesor o una profesora de historia, enseñar a enseñar historia, consiste en educar a un profesional para que tome decisiones, sepa organizarlas y llevarlas a la práctica, sobre los conocimientos históricos que debe enseñar en un aula de un centro determinado. Aprenda que enseñar historia en secundaria consiste en preparar a los jóvenes para que se sitúen en su mundo, sepan interpretarlo desde su historicidad y quieran intervenir en él con conocimiento de causa, quieran ser protagonistas del devenir histórico.

As analises realizadas pelos diferentes autores mencionados refletem preocupações semelhantes sobre os aspectos essenciais para a formação inicial e sua relação com a prática pedagógica dos novos professores em sala de aula. No Brasil há uma expressiva produção de dados oriundos de pesquisas que demonstram as fragilidades dos cursos de formação inicial, sinalizando para a necessidade de mudanças não somente nos currículos dos cursos de formação, mas também na postura dos formadores de professores, assim como nos saberes e nas práticas necessárias para a função de ser professor.

A complexidade que envolve o "ser professor" é composta por múltiplos aspectos inerentes à profissão, como dominar o processo pelo qual o conhecimento histórico é produzido, a capacidade de relacionar-se criticamente 
com o "saber conduzido" e ensinado ao aluno, a produção de um "novo saber" e a capacidade de organizar-se para a relação de ensino e aprendizagem frente aos alunos (FENELON, 1984).

Ainda de acordo com Fenelon (2008, p. 28),

Ao impacto do enfrentar o mercado de trabalho com todas as suas complexidades e todos os seus desgastantes problemas estruturais, se junta à insegurança intelectual da falta do conhecimento, da inibição para qualquer proposta alternativa, porque fora dos padrões a ele impostos como científicos. Sua perplexidade vem também do distanciamento entre as propostas de ensino de História que ele mesmo recebeu na Universidade e a realidade da formação dos alunos com os quais tem de lidar.

Nóvoa (2009), ao abordar a formação de professores para o enfrentamento das complexas especificidades do século XXI, defende alguns princípios que considera de extrema relevância para reverter o atual quadro em que se encontra a formação inicial e sua relação com a prática pedagógica nas escolas, visando à melhoria da formação de professores.

Em sua análise, defende o incentivo à criação de políticas voltadas para a formação dos professores e à valorização das culturas docentes, dos saberes e dos campos de atuação profissional. Sua crítica está voltada para a grande importância dada aos especialistas universitários, teóricos e técnicos, deixando o professor atuante nas escolas em segundo plano, com pouca voz ativa nas deliberações e ações políticas que repercutem diretamente na prática docente e no campo de atuação, assim como da exclusão dos professores atuantes nas escolas na formação dos novos professores.

Pagès (2004) acredita que há um distanciamento entre o trabalho desenvolvido pelos Professores dos Cursos de Formação em História e as necessidades da formação para a docência, aspectos negligenciados pelos cursos. Para o autor,

no es habitual que los historiadores y las historiadoras universitarios piensen en la formación de su alumnado como profesores de enseñanza secundaria. Ni tan siquiera que tengan inquietudes y preocupaciones didácticas. Son pocos los profesores y profesoras de historia que creen que existe un campo de 
problemas, y una disciplina, que tiene por objetivo investigar sobre la enseñanza y el aprendizaje de la historia en cualquier contexto educativo (también, por supuesto, en la Universidad). Y formar al profesorado para que aprenda a enseñar historia (2004, p.156).

Para reverter este quadro e fortalecer a formação docente, Nóvoa propõe a adoção de três medidas, consideradas por ele como essenciais para a superação dos dilemas atuais em relação à formação e à prática docente.

A primeira medida defendida por Nóvoa, se refere à necessidade de "passar a formação de professores para dentro da profissão". O autor defende esta medida com o argumento de que é necessário que os professores que atuam nas escolas tenham um papel central na formação dos novos professores, por meio de uma interação mais próxima e atuante em todos os percursos formativos inerentes à formação inicial, e não somente atrelada aos formadores universitários. A tendência de valorização dos "cientistas da educação" ou dos "especialistas pedagógicos" (grifos do autor) com seus saberes teóricos e metodológicos, em detrimento dos professores e seus conhecimentos práticos, precisa ser repensada.

Nesse sentido, defende a construção de uma maior aproximação e imbricação entre os professores formadores, os professores em formação e os profissionais atuantes nas escolas, salientando a ideia de conceber a formação inicial e de indução, por meio do contato com o futuro campo de atuação profissional, da reflexão coletiva entre os diferentes atores envolvidos neste processo, da mobilização de diferentes saberes, constituindo assim, um processo formativo e pedagógico de responsabilidades e compromissos mútuos.

Nesse contexto, compartilhamos da análise realizada por Fenelon (2008) sobre um dos aspectos centrais para os cursos de formação de professores, em particular, para os Cursos de História, aspecto esse quase sempre negligenciado, ou seja, a formação para a docência. Para Fenelon (2008, p. 26), na organização dos departamentos/cursos,

muito pouco se trata da discussão essencial - que tipo de profissional queremos formar, como encaramos esta formação, que objetivos devemos definir para alcançar tal propósito? De alguma forma, em muitos de nossos Cursos estas questões 
parecem já estar resolvidas e o que resta é apenas "adequar" disciplina, articular conteúdos, discutir programas.

Essas questões ficaram bastante evidentes em nossa pesquisa, especialmente nas vozes dos formadores e dos professores iniciantes, demonstrando a permanência de velhos problemas em novas realidades.

Nesse contexto, Nóvoa apresenta quatros ações que considera centrais para a concretização dessa medida: (I) estudo aprofundado de cada caso, sobretudo dos casos de insucesso escolar; (II) análise coletiva das práticas pedagógicas; (III) obstinação e persistência profissional para responder às necessidades e anseios dos alunos; (IV) compromisso social e vontade de mudança (NÓVOA, 2009, p. 18).

Segundo o pesquisador, a escola representa um espaço formativo por excelência, um espaço de compartilhamento de ideias e práticas, de supervisão e de reflexão sobre o trabalho docente. Nesse sentido, "o objectivo é transformar a experiência colectiva em conhecimento profissional e ligar a formação de professores ao desenvolvimento de projectos educativos nas escolas" (NÓVOA, 2009, p. 38).

A segunda medida defendida por este autor visa "promover novos modos de organização da profissão". Nesse panorama, o autor destaca que, a profissão docente apresenta comportamento individualista, burocrático, de controle e de regulação externa, prejudicando a importância da autonomia do professor e do trabalho por ele desenvolvido. Nesse sentido, "não é possível preencher o fosso entre os discursos e as práticas se não houver um campo profissional autónomo, suficientemente rico e aberto" (NÓVOA, 2009, p. 19). Salienta que, "a colegialidade, a partilha e as culturas colaborativas não se impõem por via administrativa ou por decisão superior" (NÒVOA, 2009, p. 19).

Assim, defende as "comunidades de prática" ou "movimentos pedagógicos" por ele considerados como elementos fundamentais para a construção do sentimento de pertencimento e da "identidade profissional" dos novos professores por possibilitar o desenvolvimento de reflexões coletivas sobre a carreira docente, auxiliando no desenvolvimento profissional. 
A terceira medida defendida por Nóvoa (2009) está embasada na necessidade de "reforçar a dimensão pessoal e a presença pública dos professores". Para o autor, nos primeiros anos de atuação profissional, o estímulo ao desenvolvimento de momentos de "auto-formação", onde os novos professores possam elaborar reflexões sobre sua vida pessoal e profissional, é um elemento importante para a construção da identidade profissional docente, pois não há separação entre o pessoal e o profissional, o professor atua em seu todo. Assim, o professor deve criar um "autoconhecimento" pessoal, relacionando-o e integrando-o ao conhecimento profissional. Defende esta medida por compreender que este é um elemento importante para a compreensão das singularidades da profissão docente, "mas também para que se construam percursos significativos de aprendizagem ao longo da vida" (NÓVOA, 2009, p. 21).

Nóvoa defende o desenvolvimento de "redes de trabalho coletivo", compreendidas como um importante suporte para uma formação docente baseada na "partilha e no diálogo profissional". Critica o aumento do consumo de eventos destinados à formação inicial e continuada, como cursos e seminários, características do "mercado da formação" tão em voga na atualidade. Segundo o autor, esse consumo é alimentado pelo constante sentimento de "desatualização dos professores".

Ao defender uma maior abertura e aproximação dos professores com o espaço público, para além dos muros das escolas, afirma que

\begin{abstract}
Os lugares da formação podem reforçar a presença pública dos professores. Tem-se alargado o interesse público pela coisa educativa. Mas, paradoxalmente, também aqui se tem notado a falta dos professores. Fala-se muito das escolas e dos professores. Falam os jornalistas, os colunistas, os universitários, os especialistas. Não falam os professores. Há uma ausência dos professores, uma espécie de silêncio de uma profissão que perdeu visibilidade no espaço público. (NÓVOA, 2009, p. 22).
\end{abstract}

A aproximação dos professores com a sociedade significa, na concepção de Nóvoa, uma mudança na comunicação estabelecida entre estes e a sociedade, aprofundando o diálogo, o reconhecimento e o prestígio público da profissão. 
"Nas sociedades contemporâneas, a força de uma profissão define-se, em grande parte, pela capacidade de comunicação com o público" (NÓVOA, 2009, p. 22).

Por sua vez, Pagès (2004) tece críticas à permanência de um modelo de ensino de História que não contempla as necessidades do mundo atual, mantendo características do ensino tradicional.

Parece que la práctica docente actual, además de compleja, no ofrece modelos demasiado innovadores a los futuros profesores de historia. Predomina una práctica transmisiva en la que la comunicación sigue siendo unidireccional - del profesor al alumno - , en la que las tecnologías de la sociedad de la comunicación y de la información penetran, si penetran, muy lentamente, y en la que, probablemente, perdura una concepción de la historia más cercana a la que predominaba a principios del siglo XX que a la que debería predominar a principios del XXI como señaló Thornton (1991b) en relación con la situación de la enseñanza de la historia en Estados Unidos, 2004, p. 160).

O rompimento com as questões sinalizadas pelo autor e a construção de currículos e práticas formativas que visem à formação de professores para o enfrentamento da complexidade representada pela sociedade atual, representa um dos grandes desafios atuais, pois requer mudanças profundas em todas as instâncias políticas, educativas e culturais diretamente relacionadas com o processo de formação de professores.

Nóvoa (2009) apresenta uma dura crítica aos excessos de discursos e a distância significativa entre os discursos e as práticas educativas nas escolas, consideradas por ele como "pobres". Uma das alternativas sugeridas pelo autor é a ampliação e reforço de saberes formativos fundamentados em investigações sobre as ações docentes e o trabalho dos professores nas escolas. Para isso, a realidade escolar e as problemáticas que envolvem o trabalho docente, requerem uma aproximação maior com o processo de formação docente. Nóvoa argumenta que: "É isto que não temos feito. É preciso começar. Parece que todos sabemos, e até concordamos, com o que deve ser o futuro da profissão docente. Mas temos dificuldade em dar passos concretos nesse sentido" (NóVOA, 2009, p. 34). Nesse contexto, questiona: "Será que o futuro ainda demora muito tempo?" 
Nesse cenário, Nóvoa defende que na fase de indução, que corresponde aos primeiros anos de exercício docente e que representa o momento mais crítico da construção da identidade docente, seja alicerçada em referenciais que permitam ao professor iniciante, compreender, analisar e desenvolver sua prática docente. O acompanhamento e supervisão de professores experientes nessa fase considerada "sensível" é o ponto alto da concepção de formação defendida pelo autor. Essas ações precisam estar acompanhadas de um consistente suporte conceitual e teórico das investigações científicas sobre formação docente e prática pedagógica.

\footnotetext{
Grande parte da nossa vida profissional joga-se nestes anos iniciais e na forma como nos integramos na escola e no professorado. Nestes anos em que transitamos de aluno para professor é fundamental consolidar as bases de uma formação que tenha como referências lógicas de acompanhamento, de formaçãoem-situação, de análise da prática e de integração na cultura profissional docente (NÓVOA, 2009, p. 37).
}

Ao propor mudanças, defende a necessidade de "devolver a formação de professores aos professores porque o reforço de processos de formação baseadas na investigação só faz sentido se eles forem construídos dentro da profissão" (p. 38). Esta concepção é justificada, pelo autor pela importância atribuída aos "professores mais experientes" que deveriam exercer "papel central na formação dos mais jovens".

\section{Considerações finais}

Os aspectos salientados pelas vozes dos professores iniciantes investigados demonstram que ainda é necessário um investimento maior no que se refere a formação de professores de História para o exercício da docência na Educação Básica. Nesse sentido, as barreiras e dificuldades enfrentadas pelos professores iniciantes no desenvolvimento da prática docente estão relacionadas à formação inicial nos cursos de História, suas limitações, omissões e resistências. 
Diante dessas questões, acreditamos que os projetos formativos dos cursos de Licenciatura em História de Mato Grosso possuem papel basilar na formação dos novos professores de História para lidar com a complexidade da sociedade atual. Defendemos que a formação para a docência nos Cursos de História necessita de maior engajamento e envolvimento do coletivo de professores formadores e maior visibilidade nos currículos dos cursos, assim como necessita de maior aproximação dos estudos realizados no curso com o campo escolar, futuro espaço de atuação dos egressos.

Acreditamos que a formação inicial e sua interlocução ou a falta da mesma com a realidade social e cultural em que se situa a escola, assim como uma maior articulação das ações desenvolvidas pelos cursos de formação inicial com os estudos sobre formação docente, repercutem na formação de significados/significações na formação dos saberes dos acadêmicos que, futuramente, produzirão também significações em seus alunos da educação básica por meio da prática docente nela desenvolvida. Nos cursos de Graduação, os conhecimentos históricos são mobilizados, reconstruídos e sistematizados. Não estamos, com isso, reduzindo a produção de conhecimentos e significações ao campo da formação inicial, porém, acreditamos que este campo/espaço de formação possui condições e ferramentas capazes de criar/desenvolver conhecimentos e, portanto, significações, nos futuros professores que darão embasamento para o trabalho docente e o diálogo com a complexa e desafiadora realidade das escolas brasileiras.

\section{Referências}

AZZI, S. Trabalho Docente: autonomia didática e construção do saber pedagógico. In: PIMENTA, S. G. (Org.). Saberes pedagógicos e atividade docente. São Paulo: Cortez, 2005, p. 35-60.

BOGDAN, R.; BIKLEN, S. Investigação Qualitativa em Educação. Uma introdução à teoria e aos métodos. Porto: Porto Editora, 1994.

DELGADO, L. de A. N. História oral, memória, identidades. Belo Horizonte: Autêntica, 2006. 
FENELON, D. R. A formação do profissional de História e a realidade do ensino. Caderno CEDES, Campinas, n. 8, p. 24-31, 1983.

p. 11-23, 1984.

A questão dos Estudos Sociais. Caderno CEDES. Campinas, n. 10,

FLORES, M. A. La Investigación sobre los primeros años de enseñanza: lecturas e implicaciones. In: GARCIA, C. M. (Org.). El profesorado principiante: inserción a la docencia. Barcelona: Octaedro, 2009, p. 59-98.

GARCIA, C. M. Formação de Professores para uma mudança educativa. Porto: Porto Editora, 1999.

HUBERMAN, M. O ciclo de vida profissional dos professores. In: NÓVOA, A. (Org.). Vida de professores. Porto: Porto Editora, 1992, p. 31-61.

MINAYO, M. C. de S. (Org.). Pesquisa Social: teoria, método e criatividade. 19 ed. Petrópolis: Vozes, 2007.

MOITA, M. da C. Percursos de formação e de transformação. In: NóvOA, A. (Org.). Vida de professores. Portugal: Porto Editora, 1992, p. 111-139.

NÓVOA, A. Professores: Imagens do futuro presente. Lisboa: Educa, 2009.

PAGÈS, J. Enseñar a enseñar história: la formación didáctida de los futuros profesores de História. Miradas a la historia: reflexiones historiográficas en recuerdo de Miguel Rodríguez Llopis. Coord. por José Antonio Gómez Hernández, María Encarna Nicolás Marín, 2004, p. 155-178.

PIMENTA, S. G. Formação de Professores: identidade e saberes da docência. In: PIMENTA, S. G. (Org.). Saberes pedagógicos e atividade docente. São Paulo: Cortez, 2005, p.15-34.

PORTELLI, A. Tentando aprender um pouquinho. Algumas reflexões sobre a ética na História Oral. Projeto História, São Paulo, n. 15, p. 13-49, abr. 1997.

Recebido NO SISTEMA em 19 de novembro de 2015 Aprovado NO SISTEMA em 18 de dezembro de 2015

( $O$ dossiê vem sendo produzido, incluindo avaliação pelos pares, desde dezembro de 2014) 